Supplement of Earth Surf. Dynam., 9, 71-88, 2021

https://doi.org/10.5194/esurf-9-71-2021-supplement

(c) Author(s) 2021. This work is distributed under

the Creative Commons Attribution 4.0 License.

(c) (1)
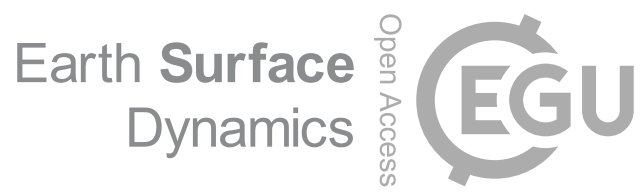

Supplement of

\title{
Different coastal marsh sites reflect similar topographic conditions under which bare patches and vegetation recovery occur
}

Chen Wang et al.

Correspondence to: Qiao Wang (wangqiao@mee.gov.cn) and Shoujing Yin (shoujingy@163.com)

The copyright of individual parts of the supplement might differ from the CC BY 4.0 License. 

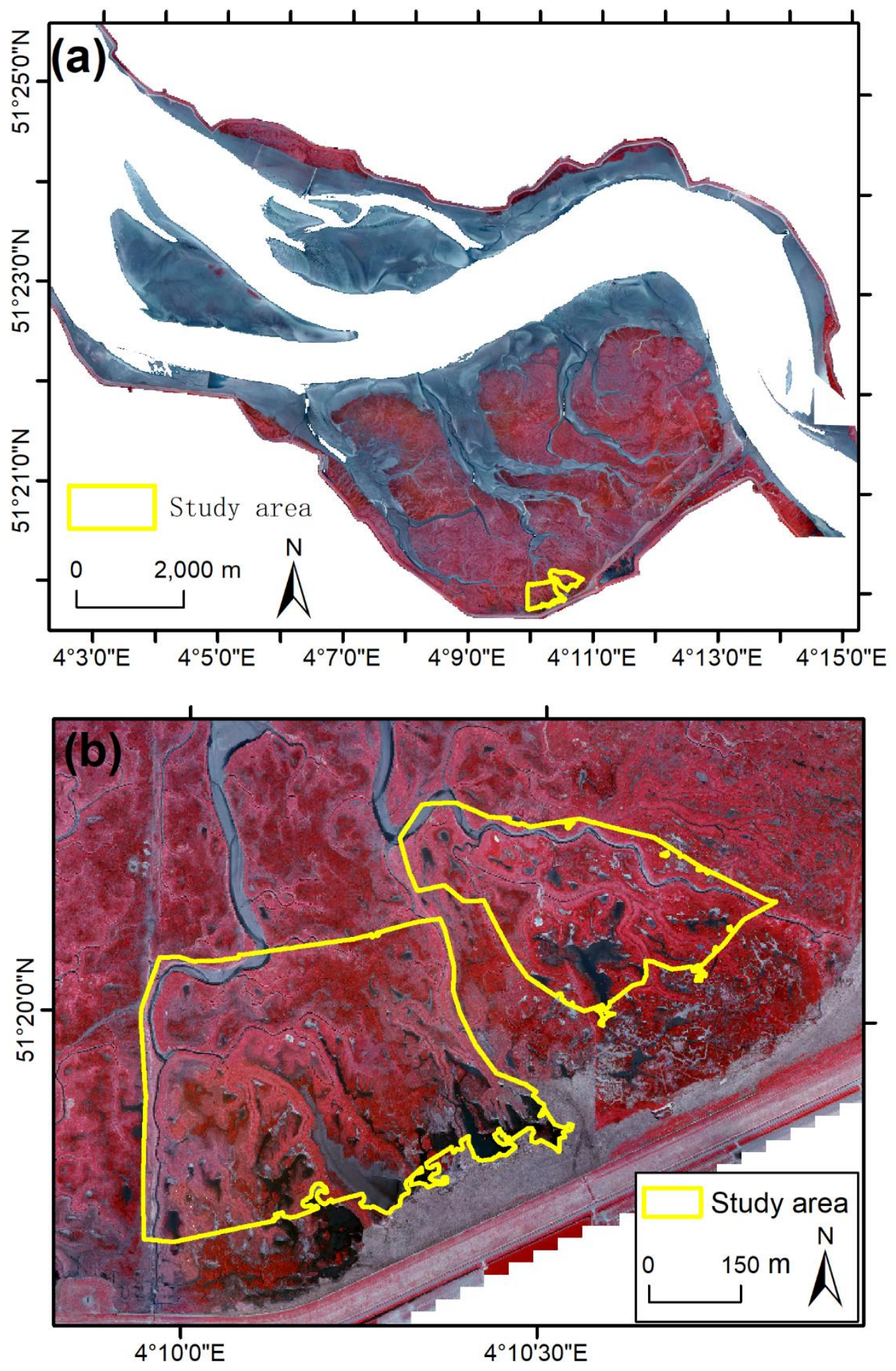

Figure S1. False-color aerial photograph of 2004 for the study area in the Saeftinghe marsh. 

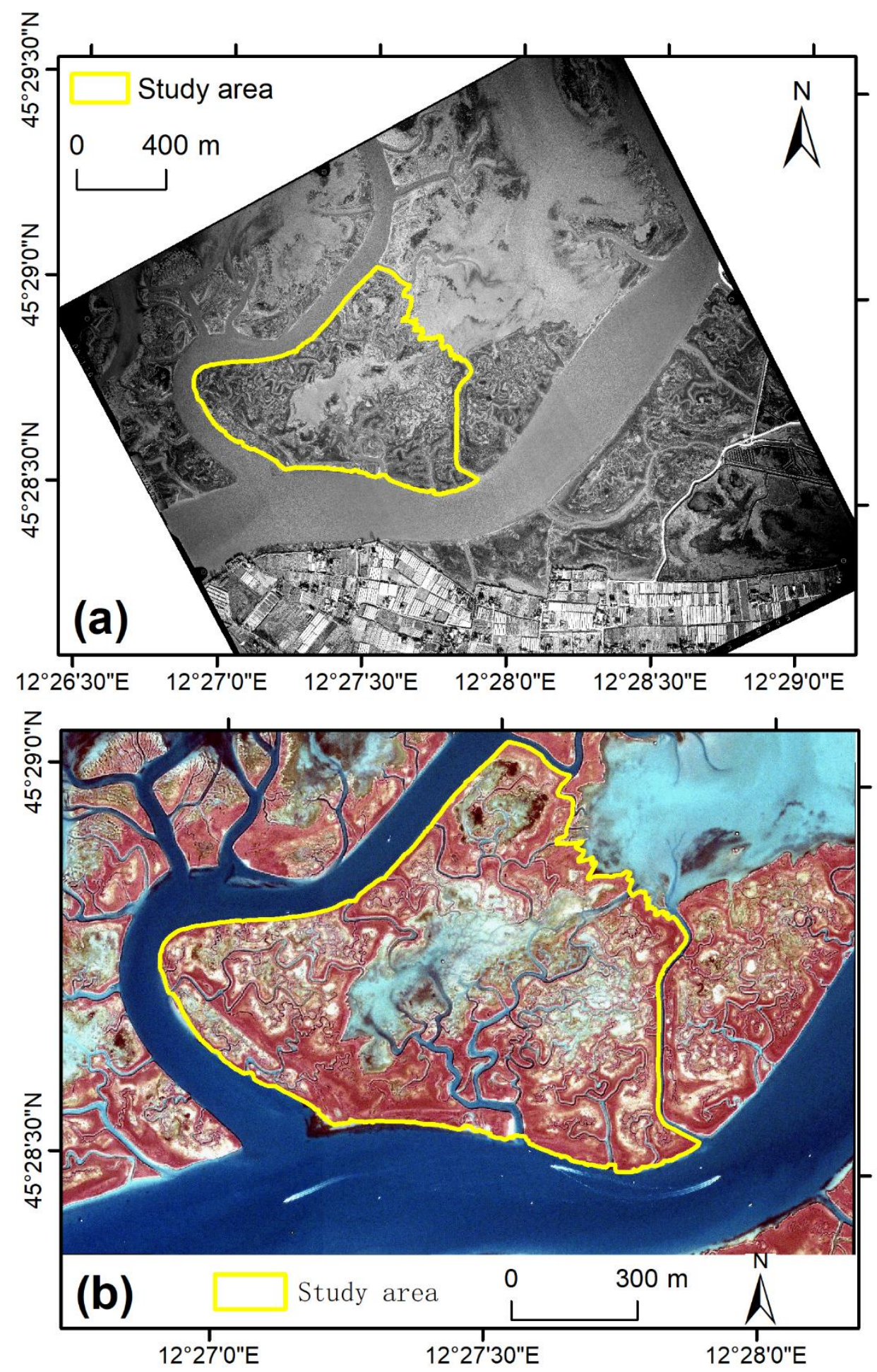

Figure S2. Aerial photograph acquired in 2000 showing the surrounding landscape (a) and IKONOS image of 2006 (b) for the study area in the San Felice marsh. 

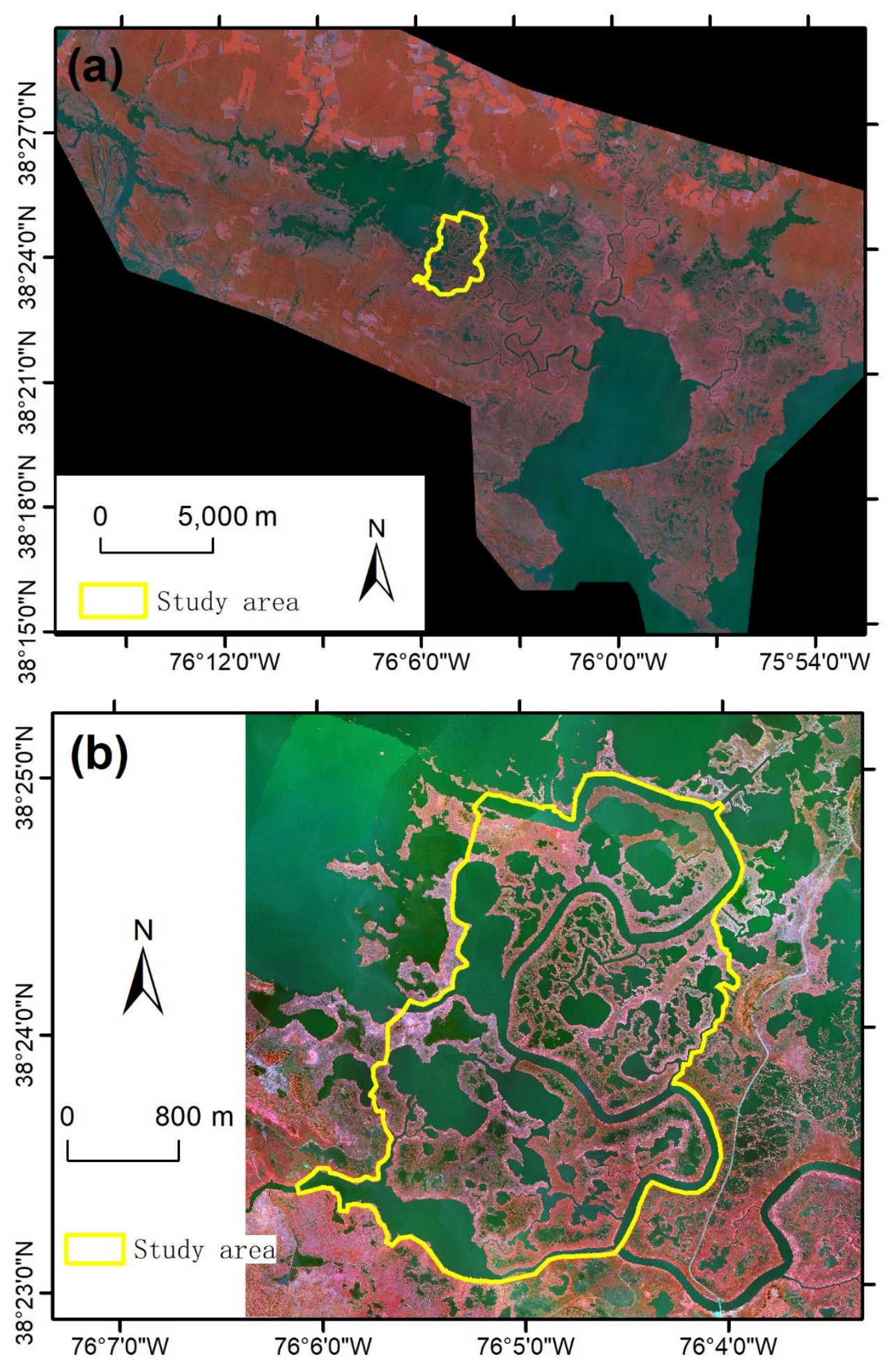

Figure S3. False-color aerial photograph of 2010 for the study area in the Blackwater Marshes. 


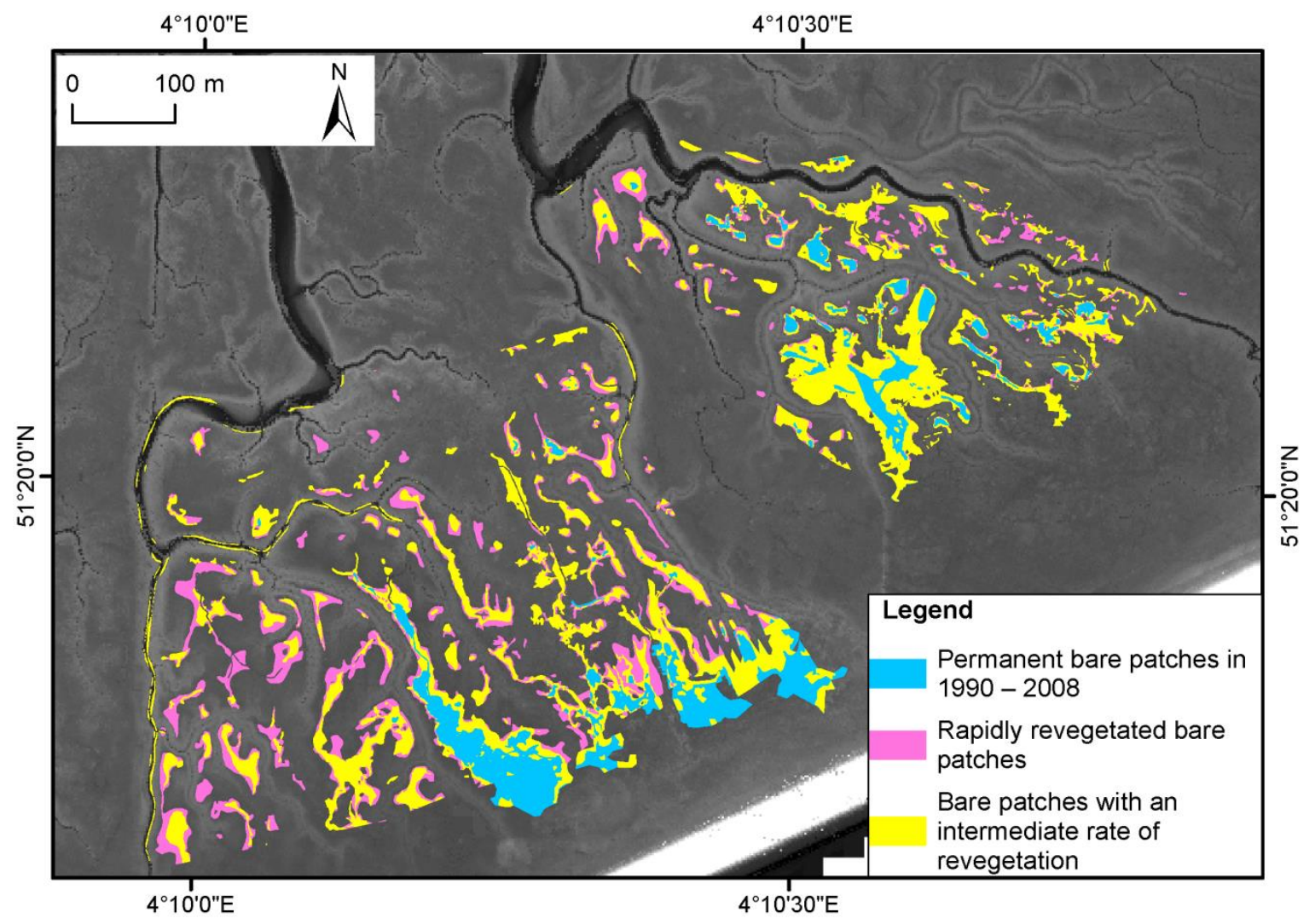

Figure S4: Spatial distribution of bare patches with a different rate of revegetation in the period of 1990-2008 in Saeftinghe. 